\title{
Comparison of Properties by Impact of Filler Materials on Carbon-Epoxy Composites
}

\author{
Shankarlinga B S ${ }^{1}$, Malikasab Bagawan ${ }^{2}$, Raghavendra ${ }^{3}$ \\ Asst. Prof, Dept. of Mechanical Engg, CMR Engineering College, Hyderabad, India ${ }^{1}$ \\ Asst. Prof, Dept. of Mechanical Engg, MVSR Engineering College, Hyderabad, India ${ }^{2}$ \\ Asst. Prof, Dept. of Mechanical Engg, Lords Institute of Engineering, Hyderabad ${ }^{3}$
}

\begin{abstract}
The desertion work describes the mechanical properties of new polymer composites consists of carbon fiber reinforcement, epoxy resin and filler materials like Zirconium Oxide $\left(\mathrm{ZrO}_{2}\right)$, Silicon Carbide (Sic), Granite Powder, Aerosil (Fumed Silica) and Coremat. The fabrication method used was conventional hand lay-up technique. The mechanical tests carried out were Tensile Test, Hardness Number and 3-P Bending Test. The Tensile Test gave the results for Tensile Strength, Tensile Modulus \& Strain. The Bending Test gave results for Flexural Strength, Flexural modulus \&Interlaminar shear strength. The test result have shown that higher the filler material volume percentage greater the strength for $\mathrm{ZrO}_{2}$, Sic, Granite Powder, Aerosil and Coremat filled carbon epoxy composites.
\end{abstract}

Keywords: Carbon-Epoxy, Zirconium Oxide, Silicon Carbide, Granite powder, Aerosil (Fumed Silica), Coremat.

\section{INTRODUCTION}

Composite materials can be well defined as an amalgamation of two or more than two materials [Reinforce, Fillers and Binders] different in composition on a very small scale. Composite material are made from two or more than two constituents with considerably differ in physical and chemical properties .when the compositions get mixture the material with appearance different from the individual components. We can say that do not lose their properties to the product causing from their mixture. The core benefits of composite materials have their great strength and stiffness, for example Carbon fibers have great specific strength, high modulus, good in fatigue resistance and dimensional stability and lower density fibers composite materials have their high strength and stiffness. If it combined with low density, when compared with bulk materials, allows for a weight reduction in the finished part.

Carbon-Epoxy composites have been of significant importance to engineering community for many years. Components made of epoxy-based materials have provided outstanding mechanical, thermal and electrical properties. Using an additional phase (ex- inorganic fillers) to improve the properties of epoxy resins has become a common practice.

\section{SPECIMEN FABRICATION}

\subsection{Materials}

\begin{tabular}{|c|l|}
\hline Matrix & $\begin{array}{l}\text { Epoxy resin: Araldite LY 556 \&Lapox T-22 } \\
\text { Hardener: HY 917 \& K6. } \\
\text { Accelerator: DY 070. }\end{array}$ \\
\hline Fiber & Carbon - Woven - 360GSM \\
\hline
\end{tabular}

\begin{tabular}{|l|l|}
\hline \multirow{4}{*}{ Fillers } & Zirconium Oxide $\left(\mathrm{ZrO}_{2}\right)$ \\
\cline { 2 - 2 } & Silicon Carbide (Sic) \\
\cline { 2 - 2 } & Granite powder \\
\cline { 2 - 2 } & Aersoil (Fumed Silica) \\
\cline { 2 - 2 } & Coremat \\
\hline
\end{tabular}

\subsection{Fabrication}

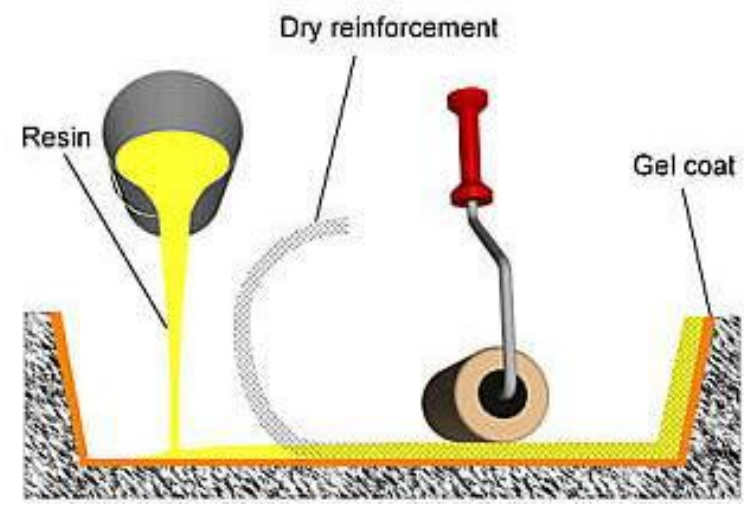

(Source:www.googleimages.com)

\section{Resin preparation -}

The required quantity of resin was taken in proper proportionate.

Weight of the fiber: weight of the resin: weight of filler $=50: 40: 10$

To this measured weight of the resin, hardener and accelerator were added such that the weight of the hardener was $10 \%$ of the total weight of the resin. The resulting mixture was properly stirred to ensure proper mixing. Addition of hardener is done to facilitate easy hardening of the composite laminate during curing. 
A flat table with glass laid on it was made ready for the laying of the material by cleaning and polishing it.

1. A release agent (wax) coat was then applied to the surface of the table to aid easy removal of the composite laminate.

2. Initially a thin coat of resin was applied on the glass.

3. A layer of 360GSM Carbon fiber was laid over it.

4. A coating of resin which was prepared initially was applied uniformly on top of the fiber.

5. Rolling was done under uniform pressure, so that the resin properly penetrates the fiber mat. A roller was used for this purpose.

6. Later second layer of carbon mat was laid, and again uniform coating of resin was applied, followed by proper rolling.

7. The process was repeated till 5 woven fiber mats were laid one over the other (with resin in between)

8. Finally a coat of resin was applied above the top mat.

9. The laminate was left for curing for 24 hours and later post cured in an oven at $1200 \mathrm{C}$ for $2 \mathrm{hrs}$.

\subsection{Specimen Dimensions:}

\begin{tabular}{|c|c|c|}
\hline Test Specimen & $\begin{array}{c}\text { ASTM } \\
\text { standard }\end{array}$ & $\begin{array}{c}\text { Dimensions } \\
(\mathbf{m m})\end{array}$ \\
\hline Tensile Specimen & D-3039 & $250 \times 25 \times 4$ \\
\hline Bending Specimen & D-790 & $110 \times 25 \times 6$ \\
\hline Impact Specimen & D-256 & $55 \times 10 \times 10$ \\
\hline
\end{tabular}

\subsection{Experimental Set up:}

The following tests were conducted in desertion work;

Tensile test,

Bending test,

Impact test,

The tests were conducted using calibrated Universal Testing Machine [UTM] as shown in fig. below,

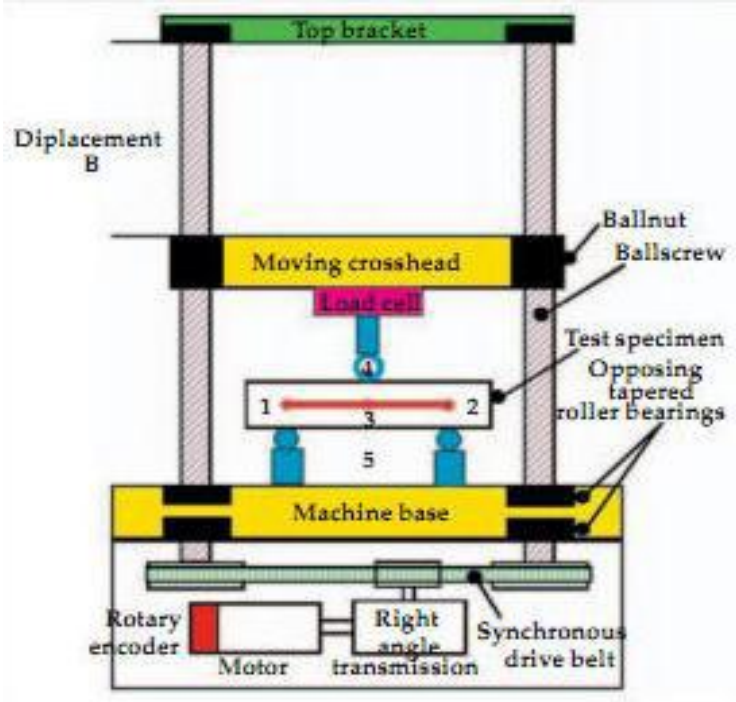

$\overline{\text { Universal Testing Machine (source; www.admet.com) }}$

\section{RESULTS AND DISCUSSION}

\subsection{TENSILE TEST}

\begin{tabular}{|c|c|c|}
\hline S. No. & Filler & $\begin{array}{c}\text { Tensile Strength } \\
(\mathbf{N} / \mathbf{m m} 2)\end{array}$ \\
\hline 1 & Untreated & $\mathbf{1 6 8}$ \\
\hline 2 & Zirconium Oxide & $\mathbf{2 0 6}$ \\
\hline 3 & Silicon Carbide & $\mathbf{1 9 2}$ \\
\hline 4 & Granite & $\mathbf{2 4 4}$ \\
\hline 5 & Aerosil & $\mathbf{2 6 2}$ \\
\hline 6 & Coremat & $\mathbf{2 0 2}$ \\
\hline
\end{tabular}

\section{Tensile Strength(N/mm2)}

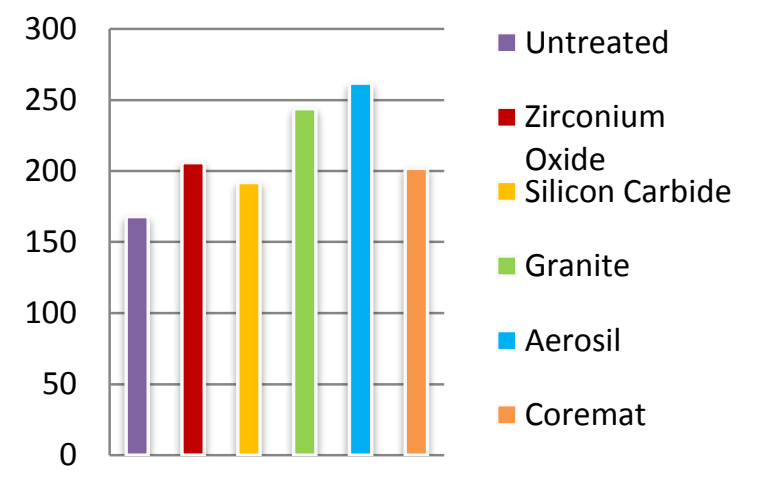

\begin{tabular}{|c|c|c|}
\hline S. No. & Filler & \% Elongation \\
\hline 1 & Untreated & 15.9 \\
\hline 2 & Zirconium Oxide & 15 \\
\hline 3 & Silicon Carbide & 14.4 \\
\hline 4 & Granite & 11 \\
\hline 5 & Aerosil & 12 \\
\hline 6 & Coremat & 23.2 \\
\hline
\end{tabular}

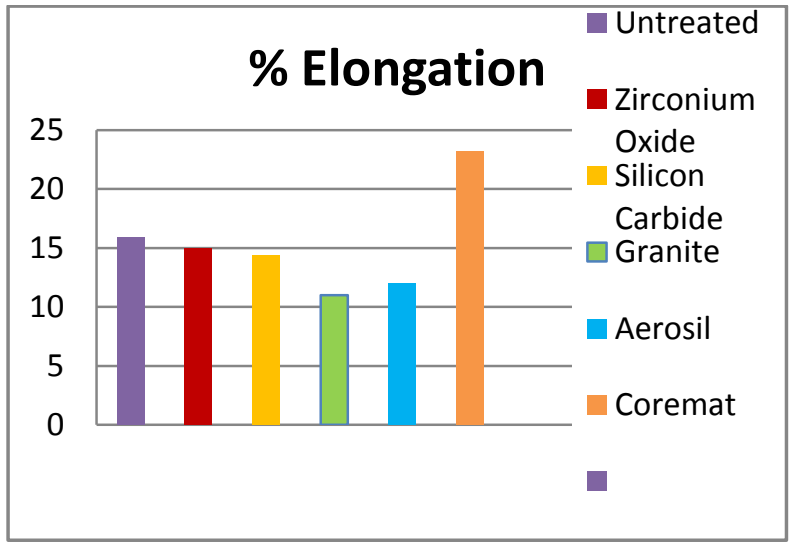

From average values table we can find that, the tensile strength \& tensile modulus in case of aerosil filled material is greater. The reason may be, since aerosil gets bonded uniformly throughout the matrix, it is able to take up higher amount of loads thereby yielding higher tensile Strength \& modulus. The $\%$ elongation is highest in case of Coremat filler, the reason being since coremat is a 
Vol. 4, Issue 2, February 2017

uniform mat laid along with carbon fiber in-line, and it takes up more strain (elongation) before failure. We can even note down that, there is no appreciable difference between granite filled \&aerosil filled composites, because both being fine powder gets bonded uniformly throughout the matrix.

\subsection{IMPACT TEST}

\begin{tabular}{|c|c|c|}
\hline S. No. & Filler & $\begin{array}{c}\text { Impact strength } \\
\mathbf{J} / \mathbf{m m}^{\mathbf{2}}\end{array}$ \\
\hline 1 & Untreated & 0.4 \\
\hline 2 & Zirconium Oxide & 0.5 \\
\hline 3 & Silicon Carbide & 0.6 \\
\hline 4 & Granite & 0.56 \\
\hline 5 & Aerosil & 0.675 \\
\hline 6 & Coremat & 0.425 \\
\hline
\end{tabular}

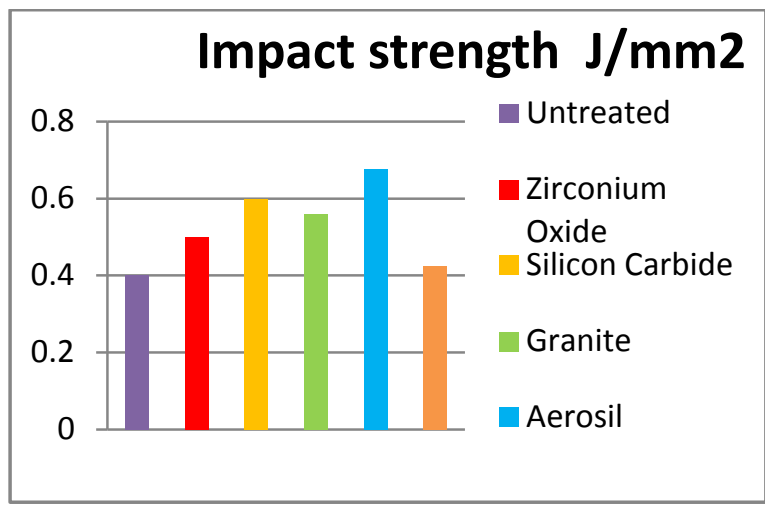

From average values of Impact test, we can find that, the Impact Strength is highest in case of aerosil filled composites, whereas Silicon Carbide filled contributes next, The reason may be, since aerosil\&Silicon Carbide powder gets bonded uniformly throughout the matrix, it is able to take up higher amount of impact loads than other filler material. In case of Coremat, Bonding strength is poor, hence it is found to be brittle \& hard.

\subsection{BENDING TEST}

\begin{tabular}{|c|c|c|}
\hline S. No. & Filler & $\begin{array}{c}\text { Flexural } \\
\text { strength N/mm }\end{array}$ \\
\hline 1 & Untreated & 2092.76 \\
\hline 2 & Zirconium Oxide & 2408.34 \\
\hline 3 & Silicon Carbide & 2696.23 \\
\hline 4 & Granite & 1900.83 \\
\hline 5 & Aerosil & 2482.16 \\
\hline 6 & Coremat & 2177.66 \\
\hline
\end{tabular}

The test was performed using 3-Point Bending test apparatus, to determine flexural strength, flexural modulus. From average values of bending test, we can find that, the Flexural strength and flexural Modulus is highest for Silicon Carbide Filled composite. In case of Aerosil theflexural strength is higher butflexural modulus is less.

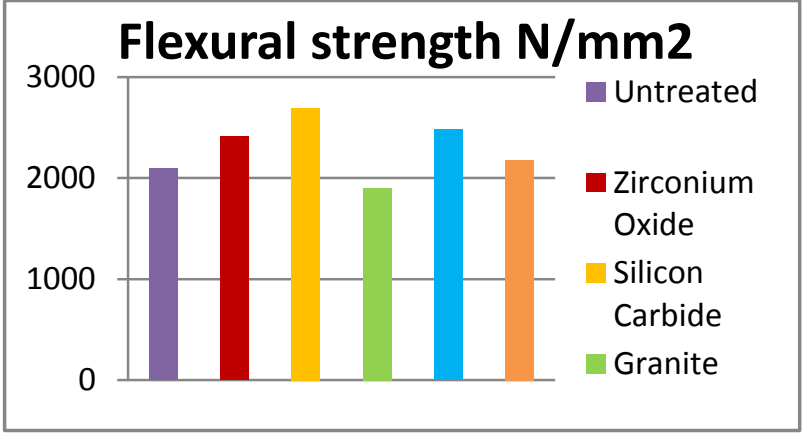

\begin{tabular}{|c|c|c|}
\hline S. No. & Filler & $\begin{array}{c}\text { Flexural moduls } \\
\mathbf{N} / \mathbf{m m}^{\mathbf{2}}\end{array}$ \\
\hline 1 & Untreated & 19100.15 \\
\hline 2 & Zr. Oxide & 22963.99 \\
\hline 3 & Silicon Carbide & 25429.78 \\
\hline 4 & Granite & 17701.46 \\
\hline 5 & Aerosil & 14296.73 \\
\hline 6 & Coremat & 17342.86 \\
\hline
\end{tabular}

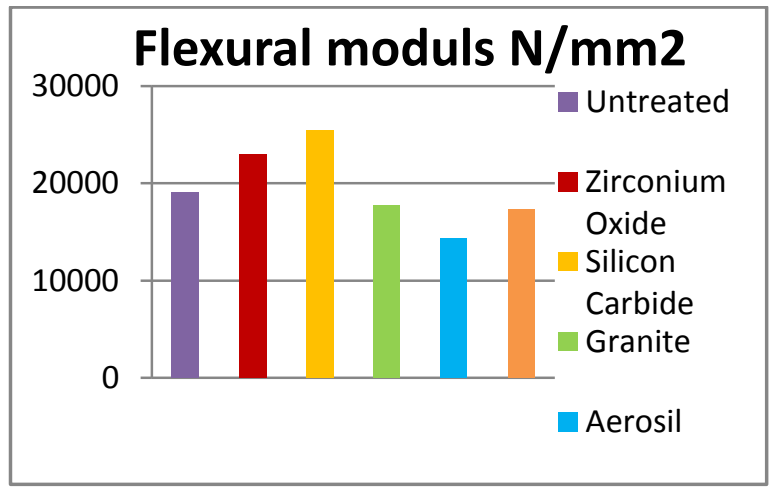

\section{CONCLUSION}

Tensile, Bending and Impact strength increases with addition of filler material.

* Sic filled composite shows significantly good results than $\mathrm{ZrO}_{2}, \quad$ Aerosil, Granite \&Corematfilled composites.

* Aerosil filled composite shows more tensile load in comparisons with unfilled andZrO $\mathrm{rr}_{2}$, Granite \&Corematfilled composites.

* Impact toughness value for Aerosi lcomposite is more than the other filled composites.

* The filler materials make material harder and brittle which is the reason for reduction in impact toughness value.

\section{REFERENCES}

[1] PatilDeogonda, Vijaykumar N Chalwa, Mechanical properties of glass fiber reinforcement epoxy composites, SMSMPITR, Akluj, India.

[2] Sumin Zhu, William G, Influence of silicon carbide particle size on the microstructure and mechanical properties of zirconium diboride-silicon carbide ceramics, University of Missouri-Rolla, USA.

[3] D.D.L. Chung, Comparison of submicron-diameter carbon filaments and conventional carbon fibers as fillers in composite materials, State University of New York. 
[4] W.kowbel, C H Shan, Mechanical behavior of carbon composites made with cold plasma treated carbon fibers, Auburn University, AL.

[5] Soo-Jin Park et al, Studies on the mechanical and mechanical interfacial properties of carbon-carbon composites impregnated with an oxidation inhibitor, Chonbuk National University, Chonju, SouthKoria.

\section{BIOGRAPHIES}

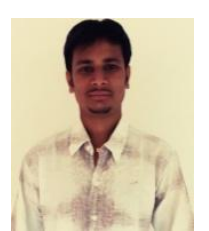

Shankarlinga B S Completed B.E degree in Mechanical Engineering (2013) at GEC Raichur, and master degree in Product Design and Manufacturing (2015) at PG center, VTU, Belagavi, He had 1.6 years of teaching experience. Currently he is working as Asst.Prof, in CMR Engineering College, Hyderabad, India.

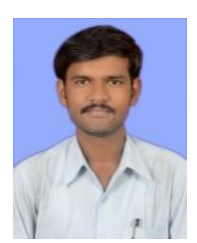

Malikasab Bagawan Completed B.E degree in Automobile Engineering (2013) at BEC Bagalkot, and master degree in Product Design and Manufacturing (2015) at PG center, VTU, Belagavi, He had 1 years of teaching experience. Currently he is working as Asst. Prof, in MVSR Engineering College, Hyderabad, India

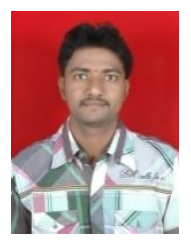

Raghavendra Completed B.E degree in Mechanical Engineering (2012) at Don Bosco institute technology, Bengaluru, and master degree in Product Design and Manufacturing (2015) at PG center, VTU, Belagavi, He had 2 years of teaching experience. Currently he is working as Asst. Prof, in MVSR Engineering College, Hyderabad, India. 